\title{
Developing Microsatellite DNA Markers in Pecan
}

\author{
L.J. Grauke ${ }^{1}$ \\ USDA ARS Pecan Breeding and Genetics, 10200 FM 50, Somerville TX 77879
}

Muhammad J. Iqbal ${ }^{2}$ and Avutu S. Reddy ${ }^{3}$
Crop Biotechnology Center, Texas A\&M University, College Station, Texas 77843-2123

Tommy E. Thompson

USDA ARS Pecan Breeding and Genetics, 10200 FM 50, Somerville TX 77879

AdDitional InDEX wORDs. Carya illinoinensis, simple sequence repeats, biodiversity

\begin{abstract}
A microsatellite-enriched library was developed from 'Halbert', a native pecan [Carya illinoinensis (Wangenh.) K. Koch] selection from Coleman County, Texas. A genomic library enriched for simple sequence repeats (SSR) containing 6144 clones was archived in 384 well plates for screening. In total, 439 clones were identified after Southern hybridization using di- and tri-nucleotide repeats as probes. In total, 125 positive clones were sequenced and primers were designed for 24 repeats. The SSR markers chosen for analysis include di- (CT and GA) and tri-nucleotide repeats (CTT, GAA and GAT). Of the 24 primer pairs tested, 19 successfully amplified microsatellites from 'Halbert'. DNA was isolated from 48 pecan and hickory accessions selected to strategically represent the genetic diversity of the National Clonal Germplasm Repository (NCGR) Carya collections. The 19 SSR primers that produced good amplification products in 'Halbert' were used to evaluate the collection, with 11 revealing polymorphism. The number of fragments amplified with different primer combinations ranged from 4 to 32 in the 48 genotypes tested. Evaluation of the data confirms the utility of the microsatellites in delimiting known relationships.
\end{abstract}

Pecan [Carya illinoinensis (Wangenh.) K. Koch] is the most valuable native North American nut crop, with a farm value of $\approx 200$ million dollars annually. The tree is a diploid $(2 n=2 x=32)$ with a genome size of $1.7 \mathrm{pg} / 2 \times$ DNA content $(\approx 1344 \mathrm{Mb})$ (Grauke et al., 2001). Species of the genus Carya occur in North America and Asia, but are thought to have originated in North America (Manchester, 1981). The greatest numbers of extant species are distributed across the southeastern United States. (Thompson and Grauke, 1991), but several species also occur in Asia (Lu et al., 1999). The USDA-ARS National Clonal Germplasm Repository (NCGR) for Pecans and Hickories, headquartered in College Station, Texas, maintains a diverse collection of Carya species from worldwide sources, with particular emphasis on native populations and cultivars of pecan (Grauke et al., 1995). Isozyme analysis has been applied to the pecan collections and has been found to be a useful tool for cultivar verification (Marquard et al., 1995) and for studying population diversity (Grauke et al., 1995; Ruter et al., 1999). The procedure is limited by the large amount of time and effort required obtaining information on a small number of loci. Conner and Wood (2001) have demonstrated the value of randomly amplified polymorphic DNA (RAPD) markers in determining genetic relationships and fingerprinting pecan cultivars. Although the technique was clearly informative, the dominantly inherited RAPD fragments are not capable of the resolution in heritability studies that co-dominant procedures would offer. Furthermore, reproducibility is dramatically influenced by reaction conditions, creating challenges when

Received for publication 9 Oct. 2002. Accepted for publication 5 Feb. 2003. The research reported in this publication was funded in part by a grant from the Fund for Rural America. Mention of a trademark, proprietary product, or vendor does not constitute a guarantee or warranty of the product by the U.S. Dept. of Agriculture and does not imply its approval to the exclusion of other products or vendors that also may be suitable.

${ }^{1}$ Research horticulturist; to whom reprint requests should be addressed; e-mail ljg@tamu.edu.

2Present address: Department of Plant, Soil and General Agriculture, Southern Illinois University, Carbondale, IL 62901.

3Present address: Dow AgroSciences Co., 9330 Zionsville Rd., Indianapolis, IN 46268. comparing results from different laboratories (Penner et al., 1993). Molecular genetic markers are needed for verification of cultivar identity, characterization of genetic diversity in relation to population origin, and as tools to aid selection of improved individuals in the breeding program. We evaluated the use of amplified fragment length polymorphisms (AFLPs) and found them to suffer the disadvantage of being non-specific: contaminant organisms such as aphids or disease, often present on field grown materials late in the season, can contribute to the DNA being amplified, producing misleading results.

An alternative technique based on the polymerase chain reaction (PCR) that has been informative in many crops uses simple sequence repeats (SSRs). Repeat regions, also known as microsatellite DNA, are composed of very short (usually 2 to 4 ) tandem repeats scattered at numerous loci throughout the genome. SSRs have been found to be highly variable and are inherited in a codominant fashion, making them very informative in population genetic analyses. Our objectives in this research were to develop molecular genetic procedures based on the PCR that would be reproducible and have the precision to separate Carya species, populations within the species range, and cultivars within species. This paper reports the development and initial evaluation of SSR markers for use in genetic studies of Carya.

\section{Materials and Methods}

Plant Material. All plants used in this research are maintained by the USDA-ARS Pecan Breeding and Genetics unit, headquartered in College Station, Texas, with a worksite in Brownwood, Texas. For the development of the genomic library, immature leaflets (from leaf burst to one-third expanded) were harvested from verified inventories of 'Halbert' pecan at the USDA-ARS-NCGR, Brownwood, Texas, immediately rinsed with water and placed in coded sample tubes on ice.

The identity and origin of the 48 accessions used in the initial evaluation of SSR markers are shown in Table 1. The accessions included parent-progeny combinations, individuals from geo- 
graphically distant native populations, species representing all Carya sections as well as the closely related genus Annamocarya (Lu et al., 1999), and interspecific hybrids (some with at least one known parent).

DNA EXTRACTION. DNA was extracted using methods of Paterson et al. (1993). The extraction buffer contained $0.35 \mathrm{~m}$ glucose, $2 \%$ (w/v)polyvinylpyrolidone (PVP), $0.1 \%(\mathrm{w} / \mathrm{v})$ diethyldithiocarbamic acid (DIECA), $0.1 \%(\mathrm{w} / \mathrm{v})$ ascorbic acid and $0.2 \%(\mathrm{w} / \mathrm{v})$ mercaptoethanol.

CONSTRUCTION AND ENRICHMENT OF GENOMIC LIBRARY.A genomic library was constructed and characterized using the methods of Connell et al. (1998). Pecan DNA ('Halbert') fragments obtained by nebulization were adapter-ligated and amplified before selection. Aliquots of the adapter-ligated expanded DNA fragments were hybridized with 5 ' biotinylated oligos of the di- and tri- nucleotide repeats: $[\mathrm{GA}] 20,[\mathrm{CA}] 20,[\mathrm{AGA}] 15,[\mathrm{CAT}] 15$ and $[\mathrm{CTA}] 15$. Hybridized fragments were incubated with streptavidin-coated paramagnetic beads (model Z5481; Promega), followed by removal of supernatant and repeated washing. Captured DNA was eluted and desalted by centrifugation. Rigorous removal of bio-

Table 1. Identity and origin of accessions evaluated using SSR markers.

\begin{tabular}{|c|c|c|c|c|c|c|c|c|c|}
\hline \multirow[b]{2}{*}{ No. } & \multirow[b]{2}{*}{ Name } & \multicolumn{3}{|c|}{ Inventory } & \multirow[b]{2}{*}{ Species } & \multicolumn{3}{|c|}{ Origin } & \multirow[b]{2}{*}{ Comment } \\
\hline & & Orchard $^{z}$ & Row & Tree & & Nation & State & County & \\
\hline$\overline{1}$ & Halbert & BW & 110 & 50.5 & illinoinensis & U.S. & TX & Coleman & pist. parent, 3 \\
\hline 2 & Halbert & BW & 111 & 44.5 & & & & & \\
\hline 3 & Wichita & CSX & 1 & 3.3 & illinoinensis & U.S. & TX & Brown & \\
\hline 4 & Mahan & CSV & 6 & 6 & illinoinensis & U.S. & MS & Attala & pol. parent, 3 \\
\hline 5 & Kernodle & $\mathrm{CSV}$ & 18 & 6 & illinoinensis & U.S. & $\mathrm{AL}$ & Tallaposa & \\
\hline 6 & Curtis & CSV & 16 & 2 & illinoinensis & U.S. & FL & Alachua & \\
\hline 7 & Moore & CSV & 2 & 4 & illinoinensis & U.S. & FL & Jefferson & \\
\hline 8 & Brooks & BW & 114 & 29 & illinoinensis & U.S. & GA & Brooks & \\
\hline 9 & Sumner & CSV & 18 & 4 & illinoinensis & U.S. & GA & Tift & \\
\hline 10 & Best's Early & CSV & 19 & 16 & illinoinensis & U.S. & $\mathrm{IL}$ & Greene & \\
\hline 11 & Hodge & CSV & 19 & 7 & illinoinensis & U.S. & $\mathrm{IL}$ & Clark & \\
\hline 12 & Posey & CSV & 9 & 12 & illinoinensis & U.S. & IN & Gibson & \\
\hline 13 & Devore & BW & 117 & 27 & illinoinensis & U.S. & IA & Louisa & \\
\hline 14 & Giles & CSV & 2 & 3 & illinoinensis & U.S. & $\mathrm{KS}$ & Cherokee & \\
\hline 15 & Greenriver & CSV & 19 & 12 & illinoinensis & U.S. & KY & Henderson & \\
\hline 16 & CS-14 & BW & 102 & 26 & illinoinensis & U.S. & LA & De Soto & \\
\hline 17 & Carman & CSV & 17 & 8 & illinoinensis & U.S. & LA & Madison & \\
\hline 18 & Van Deman & CSV & 16 & 4 & illinoinensis & U.S. & LA & St. James & \\
\hline 19 & Alley & $\mathrm{CSV}$ & 5 & 3 & illinoinensis & U.S. & MS & Jackson & \\
\hline 20 & Stuart & BW & 103 & 14 & illinoinensis & U.S. & MS & Jackson & pist. parent, 34 \\
\hline 21 & Hirschi & CSV & 19 & 14 & illinoinensis & U.S. & MO & Bates & \\
\hline 22 & Patrick & BW & 103 & 33 & illinoinensis & U.S. & $\mathrm{OK}$ & Rogers & \\
\hline 23 & Burkett & BW & 1 & 16 & illinoinensis & U.S. & $\mathrm{TX}$ & Callahan & \\
\hline 24 & Carmichael & CSV & 21 & 7 & illinoinensis & U.S. & $\mathrm{TX}$ & Gonzales & \\
\hline 25 & Evers & CSV & 11 & 13 & illinoinensis & U.S. & $\mathrm{TX}$ & Denton & \\
\hline 26 & San Saba & $\mathrm{BW}$ & 119 & 18 & illinoinensis & U.S. & $\mathrm{TX}$ & San Saba & \\
\hline 27 & Nugget & CSV & 13 & 7 & illinoinensis & U.S. & $\mathrm{TX}$ & Comanche & \\
\hline 28 & Texas Prolific & BW & 118 & 18 & illinoinensis & U.S. & $\mathrm{TX}$ & San Saba & \\
\hline 29 & Western & $\mathrm{BW}$ & 7 & 19 & illinoinensis & U.S. & $\mathrm{TX}$ & San Saba & pol. parent, 32,39 \\
\hline 30 & (XLC) EW 725 & CSV & 16 & 23 & illinoinensis $\mathrm{x}$ aquatica & U.S. & $\mathrm{TX}$ & Col.Station & \\
\hline 31 & (AQU) $88 \mathrm{AQ} 2$ & GRN & --- & --- & aquatica & U.S. & LA & Caddo & \\
\hline 32 & (XBR) RDM-3 & GRN & --- & --- & illinoinensis $\mathrm{x}$ cordiformis & U.S. & $\mathrm{TX}$ & El Paso & Western pollen \\
\hline 33 & (COR) 90-KS-2 & GRN & --- & --- & cordiformis & U.S. & $\mathrm{KS}$ & Cherokee & \\
\hline 34 & (XIM) CG 2-4 & CSV & 25 & 32 & illinoinensis $\mathrm{x}$ myristiciformis & U.S. & MS & MS State & from Stuart nut \\
\hline 35 & (MYR) 92-TX-IG & CSV & 23 & 31 & myristiciformis & U.S. & $\mathrm{TX}$ & Nacogdoches & \\
\hline 36 & (LAC) Stephens & BW & 108 & 33 & laciniosa & U.S. & KS & Unknown & \\
\hline 37 & (XNU) Wilson & CSV & 15 & 12 & illinoinensis $\mathrm{x}$ laciniosa & U.S. & MO & Nevada & \\
\hline 38 & (OVT)91-LA-1 & GRN & --- & --- & ovata & U.S. & LA & Caddo & \\
\hline 39 & (XIO) RDM-1 & GRN & --- & --- & illinoinensis $\mathrm{x}$ ovata & U.S. & $\mathrm{TX}$ & El Paso & Western pollen \\
\hline 40 & (TOM) 92LA-2G & CSV & 24 & 31 & tomentosa & U.S. & LA & Caddo & $2 n=4 x=64$ \\
\hline 41 & ILL-4 & CSP & 14 & 22 & illinoinensis & U.S. & $\mathrm{IL}$ & Greene & $\mathrm{d}$ allele for pgi \\
\hline 42 & DEV-1 & CSP & 10 & 34 & illinoinensis & U.S. & $\mathrm{TX}$ & Val Verde & $\mathrm{d}$ allele for pgi \\
\hline 43 & MX-5-1 & $\mathrm{CSP}$ & 16 & 9 & illinoinensis & MX & Tam. & Jaumave & \\
\hline 44 & $\mathrm{MX}-4-5$ & CSP & 16 & 8 & illinoinensis & MX & Hid. & Ixmiquilpan & \\
\hline 45 & $\mathrm{MX}-3-2$ & CSP & 15 & 7 & illinoinensis & MX & Oax. & Zaachila & \\
\hline 46 & MX-2-1 & CSP & 15 & 13 & illinoinensis & MX & Jal. & Sayula & \\
\hline 47 & $\mathrm{MX}-1-2$ & CSP & 14 & 7 & illinoinensis & MX & SLP & SantaCatarina & \\
\hline 48 & CAT & GRN & --- & --- & cathayensis & $\mathrm{PRC}$ & Anhwei & Shei & \\
\hline 49 & SIN & GRN & --- & --- & Annamocarya sinensis & VN & & Nho Quam & \\
\hline
\end{tabular}

${ }^{\mathrm{z} B W}=$ Brownwood, $\mathrm{CSV}=$ College Station Cultivar collection, $\mathrm{CSP}=$ College Station Provenance, CSX= College Station $\mathrm{X}$ block, GRN= greenhouse. 
tinylated oligos was accomplished by fractionation through low melting-point agarose or by multiple low speed spins through Sephadex G-50 columns. Fragments were amplified using AP-11 [5'-CTCTTGCTTAGATCTGGACTA-3'] primer (Connell et al., 1998). One microliter of material was ligated overnight with $2 \mu \mathrm{L}$ pCRII vector (Invitrogen), inactivated by heating, transformed by electroporation with $E$. coli DH10B cells, and plated on YTagar containing $100 \mu \mathrm{g}$ amipcillin/mL. Plates were treated with X-GAL and IPTG for blue/white colony selection. After growing overnight, white colonies were picked and archived into 384-well microtitre plates.

SCREening OF LIBRARY FOR Microsatellites. Four 384-well microtitre plates were used to prepare one $8 \times 12 \mathrm{~cm}$ size HybondN+ filter in a $3 \times 3$ grid, duplicating each plate and leaving the center blank. Filters were spotted using a Beckman Biomek 2000 Automated Laboratory Workstation interfaced with a 384-pin tool. Spotted colonies were grown overnight on filters placed on ampicillin treated YT-agar media. Filters were processed to lyse bacteria and fix nucleic acids to the filter, followed by air-drying. Filters were screened by hybridization at $60{ }^{\circ} \mathrm{C}$ overnight using end-labeled ( $\left.{ }^{32} \mathrm{P}\right)$ SSR-oligonucleotides as probe. Positive clones were catalogued and assigned number designations according to position of the grid.

One hundred twenty-five positive clones were sequenced on an ABI 377 automated DNA sequencer. Of these, 24 repeats had long enough sequence at the two ends to design primers. Primers were designed using Primer Express (Applied Biosystems, Inc.) software, and were synthesized by Genosys. The SSR markers chosen for primer analysis include di- (CT and GA) and tri-nucleotide repeats (CTT, GAA, and GAT). Markers were amplified under high stringency conditions with temperatures based on length and GC content. Reproducibility was verified using 'Halbert' DNA isolated from different inventories.

PCR AMPlifiCATION OF MiCrosatellite LOCI. The genomic DNA of 48 accessions (Table 1) was amplified in a Perkin Elmer 9600 thermal cycler. Amplifications were performed in $10-\mu \mathrm{L}$ reaction volume containing $10 \mathrm{~mm}$ Tris- $\mathrm{HCl}\left(\mathrm{pH} 8.3\right.$ at $\left.25^{\circ} \mathrm{C}\right), 50 \mathrm{~mm} \mathrm{KCl}$, $2.0 \mathrm{~mm} \mathrm{MgCl} 2,0.16 \mathrm{~mm}$ each of dATP, dGTP, and dTTP, 0.016 mM of dCTP(Promega), $0.04 \mu \mathrm{L}$ of $3000 \mathrm{Ci} / \mathrm{mmol}^{33} \mathrm{P}$ or ${ }^{32} \mathrm{P} \mathrm{dCTP}$ (Amersham), $30 \mathrm{ng}$ of each forward and reverse primer, 0.5 unit of Taq DNA polymerase (GIBCO-BRL) and $30 \mathrm{ng}$ of template DNA. The SSR primers that produced amplification products in 'Halbert' were used to evaluate the collection. For the PM-CIN04 marker, $5 \%$ triton $\times 100$ was also used in the amplification mixture. Amplifications were carried out with first denaturation at $94{ }^{\circ} \mathrm{C}$ for 3 min followed by 35 cycles of $94{ }^{\circ} \mathrm{C}$ for $30 \mathrm{~s}, 55$ to $60{ }^{\circ} \mathrm{C}$ for $30 \mathrm{~s}$, and $72^{\circ} \mathrm{C}$ for $1 \mathrm{~min}$. In some cases, 35 cycles of amplification were carried out by two step PCR with $94^{\circ} \mathrm{C}$ for $30 \mathrm{~s}$ and $65^{\circ} \mathrm{C}$ for 1 min and $30 \mathrm{~s}$. In all cases, final extension was carried out at $72{ }^{\circ} \mathrm{C}$ for $3 \mathrm{~min}$. The reactions were kept at $4{ }^{\circ} \mathrm{C}$ until removed from the thermal cycler. An equal volume $(10 \mu \mathrm{L})$ of manual sequencing loading dye [98\% deionized formamide, 10 mm EDTA ( $\mathrm{pH} 8.0)$, $0.025 \%$ xylene cyanol FF, $0.025 \%$ bromophenol blue] was added to the PCR product.

For gel electrophoresis and visualization, the samples were heated at $94{ }^{\circ} \mathrm{C}$ for 3 to $4 \mathrm{~min}$, chilled on ice and 2 to $3 \mu \mathrm{L}$ of each was electrophoresed on $5 \%$ denaturing acrylamide gel using $0.5 \times \mathrm{TBE}$ buffer (45 mm Tris-borate, $1 \mathrm{~mm}$ ethylenediamine-tetraacetic acid) at $60 \mathrm{~W}$ for $1.5 \mathrm{~h}$ or until the blue dye reached the lower tank buffer. The gel was transferred to $3 \mathrm{MM}$ blotting paper, dried in a vacuum dryer and exposed to X-ray film for $12 \mathrm{~h}$ at $-80{ }^{\circ} \mathrm{C}$ to detect ${ }^{32} \mathrm{P}$-labeled products.
DATA SCORING AND ANALYSIS. The autoradiographs were scanned as TIFF files and were analyzed by RFLPscan software to aid in gel scoring (sizing amplified fragments, and comparing amplification profiles). Scoring was also done independently by a second person using visual analysis. Consensus was achieved by manual comparison of automated scores with the gel pictures, and qualitative data $(1=$ presence, $0=$ absence $)$ were entered into matrices for analysis using NTSYSpc (Numerical Taxonomy and Multivariate Analysis System, Version 2.02) software. A similarity matrix was computed using the Jaccard coefficient (which compares on the basis of fragments present, rather than those absent; Aldenderfer and Blashfield, 1984) in the SIMQUAL module (Similarity for Qualitative data) of NTSYSpc. Sequential, Agglomerative, Hierarchical, and Nested Cluster analysis was performed using the similarity matrix in the SAHN module using the single-link, complete-link, and UPGMA (unweighted pair-group method, arithmetic average) options. Clusters formed using the single-link and complete-link option methods were used to plot a strict consensus tree, using the CONSEN module. A cophenetic value matrix was computed from each cluster analysis using the COPH module, and was compared with appropriate similarity matrix using the MXCOMP module, to generate an $r$ value for interpretation of cophenetic correlation. The phenograms produced by cluster analyses were plotted using the TREE module.

\section{Results and Discussion}

DEVELOPMENT OF SSR MARKERS. Of the 24 primer pairs tested, 19 successfully amplified microsatellites from 'Halbert'. The primer sequence and size of amplified fragments for those 19 are shown in Table 2. Amplified fragments for some primers (e.g., PM-GA23 F, PM-GA31 F, PM-GA38 F, PM-GA41F, PM-GA44F, PM-GA54F, PM-GA19F, PM-CIN13F, PM-CIN20R and PM-CIN27F) include repeat sections that continue into the annealing primers. Amplified regions for some markers include complex repeat sequences of more than one type and with large non-repeating regions (e.g., PM-CA12). Other markers were associated with regions that were very uniform in the repeat sequence and devoid of extraneous, non-repeating sequences (perfect repeats; e.g., PM-GA54, PM-GA19).

Overlap of the repeat sequence into the annealing primer creates a potential liability in the performance of the primers that will be addressed in continued research. Modification of primer sequences and optimization of amplification conditions could contribute to the production of more distinct profiles, simplifying their scoring and interpretation. It would be informative to isolate and sequence variable fragments from the SSR profiles to characterize sources of polymorphisms.

Characterization of Markers. When the 19 SSR markers were used to evaluate the diverse collection of 48 accessions, 11 revealed polymorphisms (variation in fragment profiles) that allowed differential scoring (e.g., Fig. 1). With 48 genotypes scored for 11 primer combinations, there were 528 possible SSR profiles. However, 34 profiles $(6.4 \%)$ could not be scored due to poor amplification. Only one primer combination, PM-CIN20, amplified across all species, while others failed to amplify particular accessions. Failure to amplify was not limited to particular species. PM-CA07 failed to amplify in 10 accessions in three species, missing the greatest number of accessions, while PM-CIN4 failed to amplify in one accession of each of 4 species, missing the greatest number of species. Among the hickory species, there were a total of 10 failures from 143 possible profiles (7\% failure). Carya cordiformis was the species most commonly failing in amplification. 
Amplification challenges were also observed with pecan, which had 24 profiles that failed from a possible 385 (6.2\% failure). Among pecan accessions, the greatest problem with amplification was with 'Greenriver', which failed to amplify for eight primer combinations, followed by 'Carman', which failed in five. When 'Greenriver' and 'Carman' were removed from the analyses, matrix correlations between cophenetic values and similarity values improved, so they were removed from subsequent analysis. 'San Saba' and 'Hodge' each failed in two primer combinations, with 'Moore', 'Brooks', 'Posey', 'Stuart', 'Hirschi', and 'Carmichael' each failing for a single primer combination.

Given differences in amplification between accessions, questions arose concerning the density of fragments to be scored. If amplification of an accession's DNA was faint, but fragments were visible, they were scored. The number of fragments scored for different markers ranged from 4 to 32 in the 48 genotypes tested, with a total of 133 fragments scored in the 11 primers. Combinations of fragments resulted in various patterns that were often found in multiple accessions. For some primers (e.g., CIN20, Fig. 1) patterns were simple combinations of each fragment, such that although four fragments were scored, the combination of two or three fragments in a profile resulted in a total of six observed patterns (Fig. 1) that are easily given allelic interpretation. Other primers (e.g., GA39, Fig. 1) were much more complex in the number of fragments present, with blurring of fragments further complicating scoring and allelic interpretation. Twenty-five patterns were identified in that primer,

Table 2. Base sequence and characteristics of annealing primers for 19 SSR markers developed from 'Halbert' pecan.

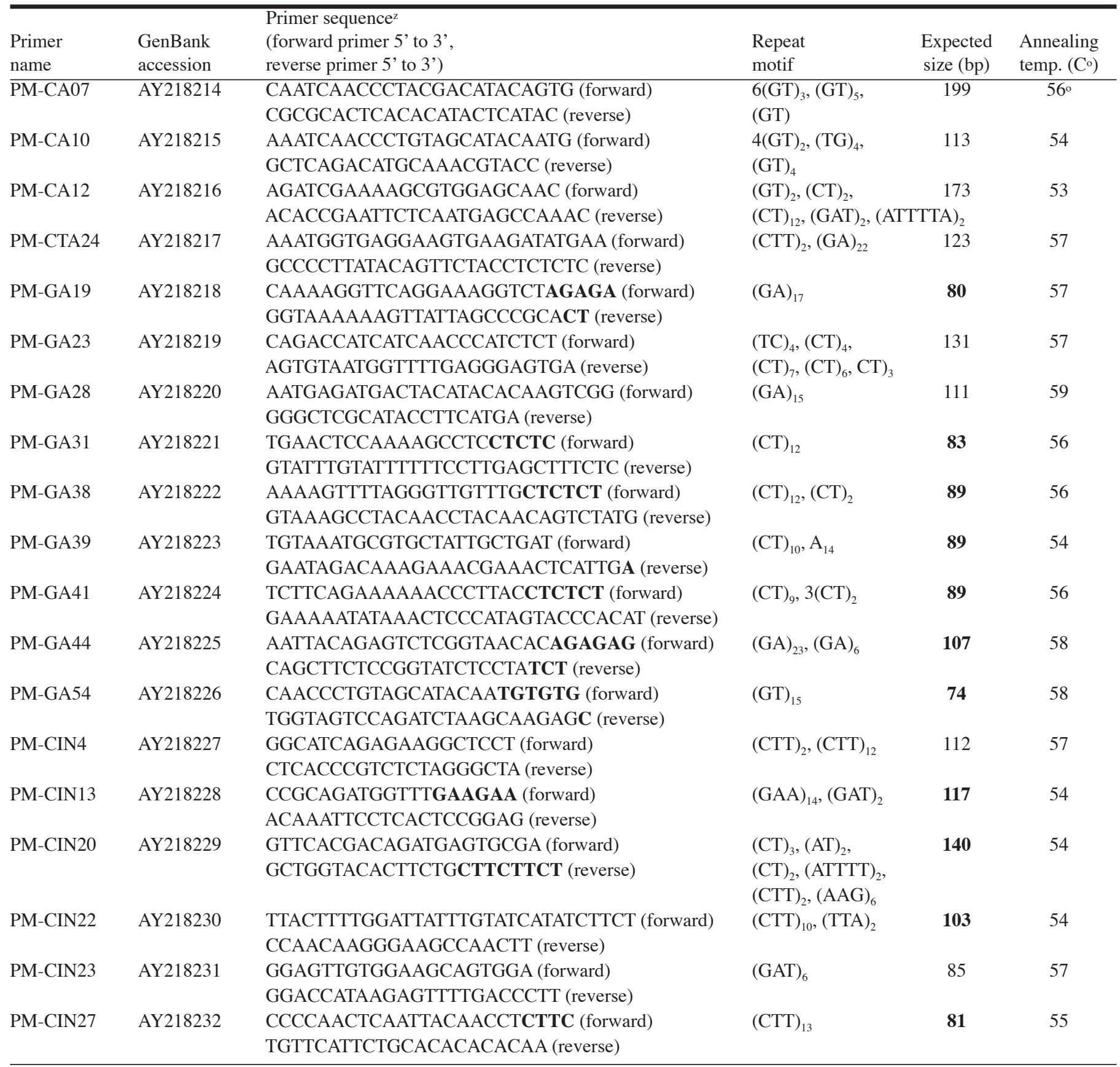

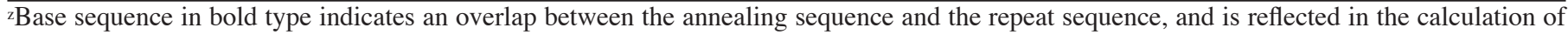
total fragment size, also shown in bold. 
with 16 observed among pecan accessions and 11 observed among the hickory accessions (including hybrids). Since two patterns were shared by pecan and hickory accessions, there was a total of 25 different patterns. Generally, the shared patterns were observed in hybrids, although some hickory species, especially C. aquatica, often exhibited a pattern common in pecan.

Successful amplification must be coupled with the presence of unique profiles (polymorphism) to allow separation of accessions. The occurrence of unique individual fragments insured a unique profile, although unique profiles could also occur with a combination of fragments that were present in other accessions and were therefore not unique to the accession. Unique fragments were associated with each species and hybrid, with the exception of $C$. myristiciformis and its putative hybrid (XIM). Carya myristiciformis was characterized by unique profiles in three primers (CIN4, CIN20, GA39). The putative interspecific hybrid between pecan and $C$. myristiciformis (XIM) could not be distinguished from pecan in any primer, raising questions of its identification as a hybrid. Disregarding pecan, the species with the greatest number of unique fragments was $C$. tomentosa (the only tetraploid species represented) which had eight, followed by the Asian species $C$. cathayensis, with six. Several species-hybrid groups $(C$. aquatica and C. x lecontei; C. cordiformis and C. x brownii; $C$. ovata and $C$. illinoinensis $\times$. ovata) shared unique fragments that were not found in any other accessions. When interspecific hybrids were removed from cluster analyses, matrix correlations between cophenetic values and similarity values increased across all linkage grouping procedures tested: from $r=0.6577$ to 0.7395 for complete linkage analysis; from $r=0.8628$ to 0.8770 for single linkage analysis; and from $r=0.8990$ to 0.9144 for UPGMA linkage analysis (Fig. 2).

SPECiES DifFERENTIATION. One objective of this work was to develop molecular markers capable of distinguishing between Carya species. Some primers (e.g., PM-CIN20) amplified across all accessions tested, were polymorphic, and were easy to score. PM-CA10 successfully amplified at least some accessions in all species tested, and was polymorphic between species although monomorphic for pecan. PMCIN22 was particularly informative in relation to interspecific hybrids, with unique patterns associating hybrids with the hickory species parent in two hybrid families (C. illinoinensis $\mathbf{X}$ C. aquatica, and C. illinoinensis $\times$ C. ovata).

The phenogram of UPGMA linkage analysis (Fig. 2) reveals a definite hiatus between pecan and other hickories, as is expected on the basis of known levels of relatedness. The species most closely associated with pecan in this analysis was $C$. aquatica, which readily hybridizes with pecan when the two species are sympatric. The lowest affinity with pecan was between the weak group formed by $C$. cordiformis and Annamocarya sinensis (Fig. 2). Manos and Stone (2001) found C. cordiformis to be the Carya species most closely related to pecan (C. aquatica was not included in that analysis) based on direct sequencing of the nuclear ribosomal internal transcribed spacer (ITS) region. Annamocarya was the most distantly related species in the assemblage formed by Carya species, and formed the closest associations with other Asian species $C$. cathayensis and $C$. tonkinensis. When those authors compared assemblages based on chloroplast DNA intergenic spacer sequences, neither pecan and $C$. cordiformis, nor the Asian species were as closely grouped. However, it is difficult to compare our results with those from the above study since the methods and objectives were so vastly different (Rohlf and Sokal, 1981). Our results support the possibility that genetic diversity of the genus and introgression of genes into particular populations can be studied using these molecular tools, after further refinement. Specific primers such as PM-CA10, PM-CIN20 and PM-CIN22 appear to be particularly informative in relation to species level distinctions while being less useful for separation of pecan accessions.

Distinguishing Populations. Another objective of this work was to develop markers capable of distinguishing between populations. Seedling pecan accessions originating from the central region of Mexico in Santa Catarina, San Luis Potosi (MX-1), Zaachila, Oaxaca (MX-3), and Ixmiquilpan, Hidalgo (MX-4) grouped into a relatively distinct assemblage (Fig. 2), despite their wide geographic distribution. The western-most Mexican accession, MX-2 (from Sayula, Jalisco), formed a cluster with several northern pecan cultivars (Hirschi, Posey, and Best's Early). The eastern-most Mexican accession, MX-5 (from Jaumave, Tamaulipas) was more closely associated with pecans of eastern origin ('Stuart', CS-14, and 'Van Deman'). Using 13 polymorphic allozyme loci to study genetic relatedness of these same populations, Ruter et al. (1999) reported the closest association between populations MX-1 and MX-4, while

Fig. 1. banding patters of three simple sequence repeat markers developed for pecan. Lanes are ordered from left to right as shown in Table 1, excluding sample 2 .
$-\mathrm{PM}-\mathrm{CIN} 4$

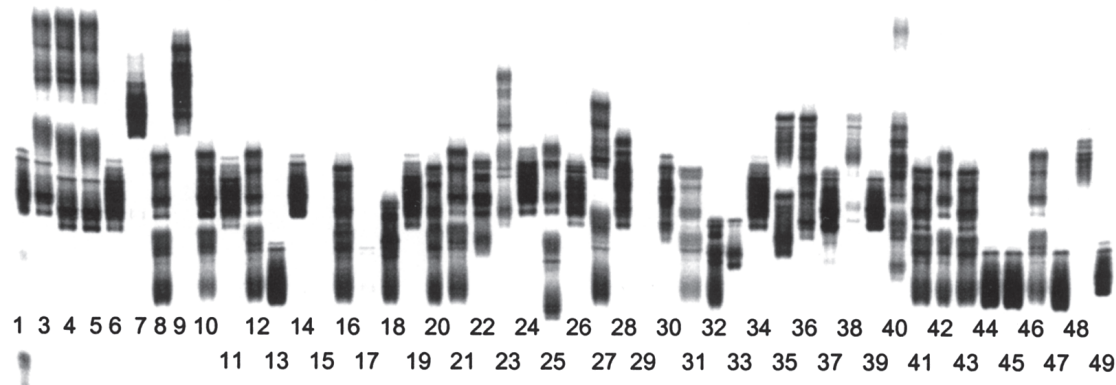

PM-GA39

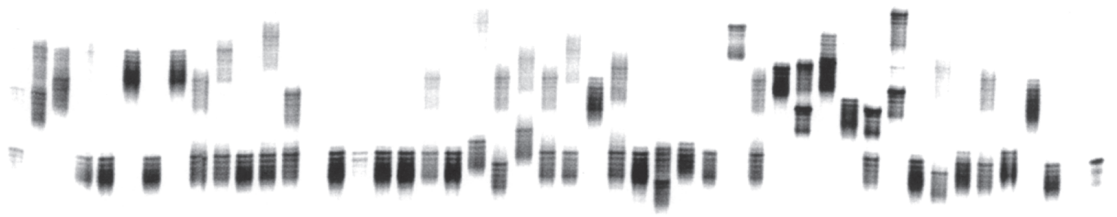

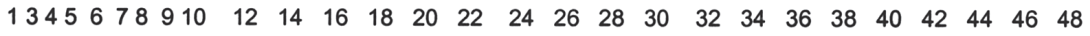
$\begin{array}{llllllllllllllllllll}11 & 13 & 15 & 17 & 19 & 21 & 23 & 25 & 27 & 29 & 31 & 33 & 35 & 37 & 39 & 41 & 43 & 45 & 47 & 49\end{array}$

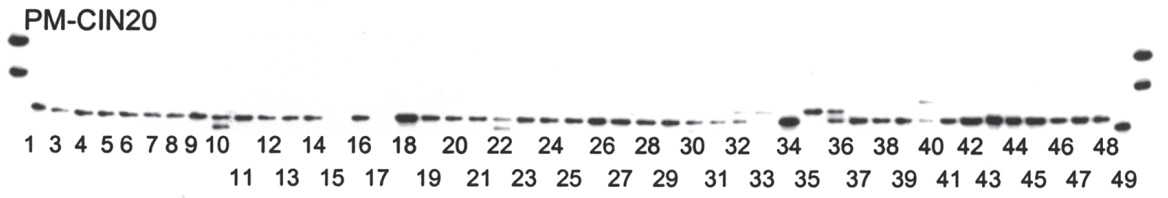




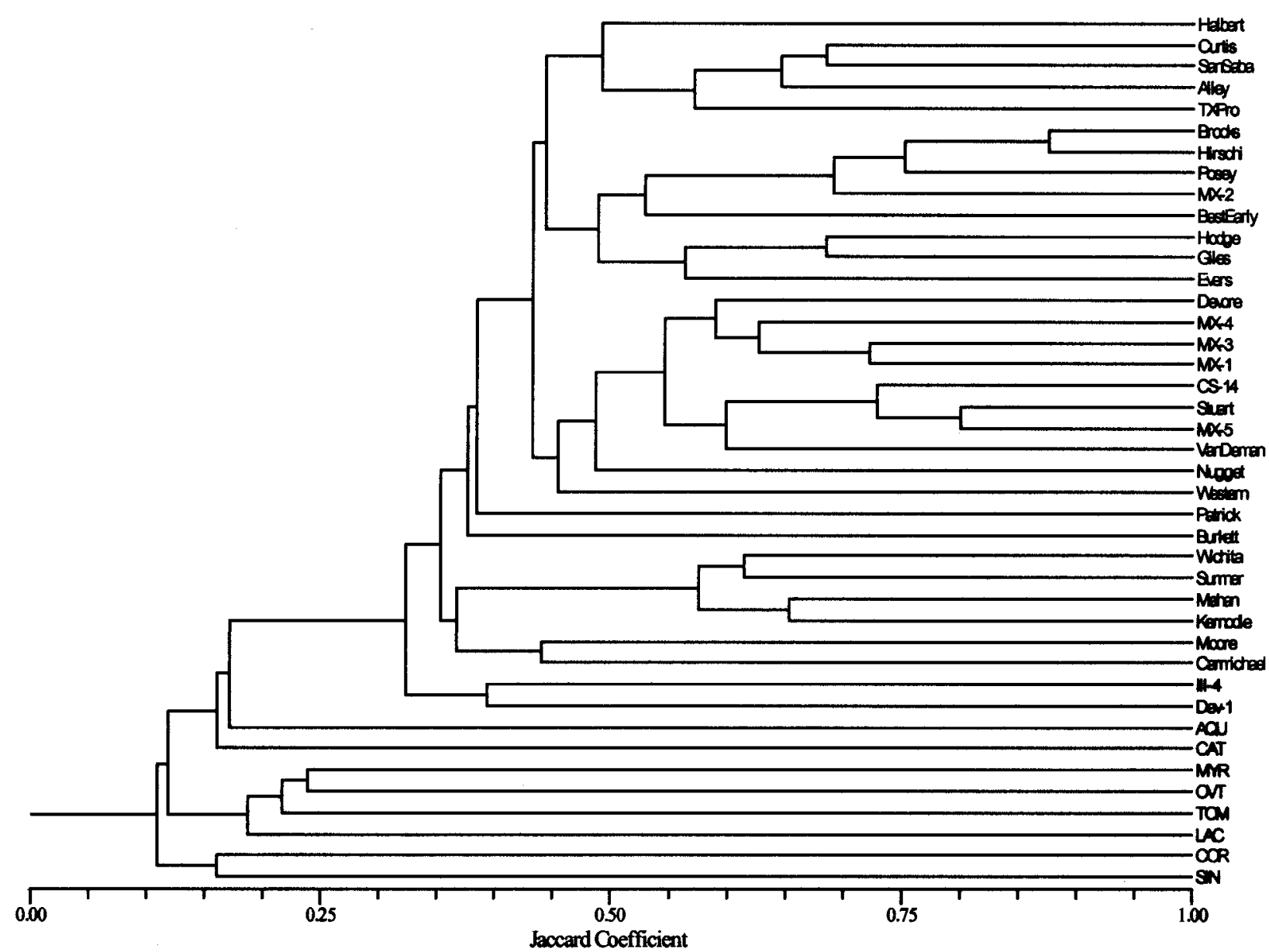

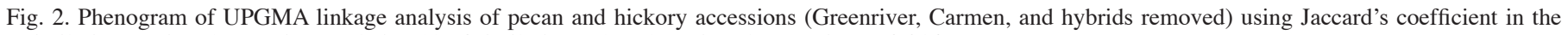
similarity matrix. The matrix correlation $(r)$ of similarity and cophenetic value matrices $=0.914$.

MX-2 and MX-3 formed a separate, more distant assemblage. Their work was based on the analysis of 230 individuals from the five Mexican populations. The current report, using only 5 individuals to represent those populations, is not intended to offer definitive interpretation of population relatedness.

There was no clear separation of United States pecan cultivars on the basis of geographic origin. The current study included a broad sampling of the genetic and geographic diversity of pecan, but is not the appropriate sample to critically evaluate these molecular tools in relation to provenance level distinctions. It would be helpful to have larger numbers of accessions from structured collections of native populations to more adequately evaluate the utility of these markers for that application. However, the close clustering of the three central Mexico accessions is a promising indication of the utility of these tools for population level distinctions.

Fingerprinting ACCESSIONS. Possibly the most immediately applicable objective of this research was to develop molecular genetic tools capable of "fingerprinting" cultivars as an aid to identification and verification. Within the 35 pecan accessions evaluated, several had unique fragments and all had unique profiles. 'Sumner', 'Patrick', 'Carmichael', and 'Evers' each had two fragments found in no other accession, while 'Moore', 'Brooks', 'Best's Early', 'Burkett', 'Nugget', 'Western', and MX5-1 each had one unique fragment.

Known parent progeny combinations showed a wide range of similarities: 'Wichita', the progeny of 'Halbert' and 'Mahan' showed similarities of 0.481 and 0.630 with those two cultivars, respectively.
'Western' pecan was used as a parent for two interspecific hybrid accessions (XBR and XIO) (Table 1). 'Western' had the highest similarity rating for XIO (0.500) and was among the highest for XBR (0.414), although another pecan accession ('Van Deman') had higher similarity ratings (0.429).

The highest similarity observed among pecan accessions was 0.875 , between 'Brooks' and 'Hirschi', two cultivars with no known kinship. Disregarding accessions with amplification problems such as 'Greenriver' and 'Carman' (each of which showed zero similarity with particular accessions) the lowest similarity observed between pecan accessions was 0.086 between 'Kernodle' and Dev-1, cultivars originating at the eastern and western extremes of pecan range, respectively. The lowest overall similarity was 0.035 between $C$. myristiciformis (MYR) and 'Western'.

Using 100 RAPD markers, Conner and Wood (2001) were able to uniquely identify 43 pecan cultivars, and reported similarity coefficients ranging from 0.91 to 0.46 . Those researchers used the Dice similarity coefficient, while we used Jaccard's coefficient, resulting in our generally lower similarity values. As in our results, they found the highest similarity values between cultivars with no known relationship ('Schley' and 'Mahan').

The resolution of individuals across this diverse assemblage of accessions is promising. These SSR markers should be a valuable tool in the verification of cultivar identity. However, it will be necessary to evaluate a broader collection of more closely related cultivars to critically quantify the resolution of this technique for fingerprinting cultivars. For these microsatellite markers to be used 
in genetic fingerprinting for cultivar verification, the procedures for scoring and fragment designation will need substantial improvement and testing.

\section{Literature Cited}

Aldenderfer, M.S. and R.K. Blashfield. 1984. Clusteranalysis. Sage Univ.Paper Ser. Quant. Appl. Soc. Sci. No. 07-044. Sage, Beverly Hills, Calif.

Connell, J.P., S. Pammi, M J. Iqbal, T. Huizinga, and A.S. Reddy. 1998. A high through-put procedure for capturing microsatellites from complex plant genomes. Plant Mol. Biol. Rptr. 16:341-349.

Conner, P.J. and B.W. Wood. 2001. Identification of pecan cultivars and their genetic relatedness as determined by randomly amplified polymorphic DNA analysis. J. Amer. Soc. Hort. Sci. 126:474-480.

Grauke, L.J., H.J. Price, and J.S. Johnston. 2001. Genome size of pecan determined by flow cytometry. HortScience 36:814.

Grauke, L.J., T.E. Thompson, and R.D. Marquard. 1995. Evaluation of pecan [Carya illinoinensis (Wangenh.) K. Koch] germplasm collections and desgination of a core subset. HortScience 30:950-954.

Lu, A., D.E. Stone, and L.J. Grauke. 1999. Juglandaceae, p. 277-285. In: Z.Y. Wu and P.H. Raven (eds.). Flora of China. vol. 4. Cycadaceae through Fagaceae. Science Press, Beijing, and Missouri Botanical Garden Press, St. Louis.
Manchester, S.R. 1981. Fossil history of the Juglandaceae. PhD diss. Ind. Univ., Bloomington.

Manos, P.S. and D.E. Stone. 2001. Evolution, phylogeny, and systematics of the Juglandaceae. Ann. Mo. Bot. Gard. 88:231-269.

Marquard, R.D., L.J. Grauke, T.E. Thompson, and R.S. Janos. 1995. Identifying pecan cultivars by isozymes and inheritance of leucine aminopeptidase. J. Amer. Soc. Hort. Sci. 120:661-666.

Paterson, A.H., C.L. Brubaker, and J.F. Wendel. 1993. A rapid method for extraction of cotton (Gossypium spp.) genomic DNA suitable for RFLP or PCR analysis. Plant Mol. Biol. Rptr. 11:122-127.

Penner, G.A., A. Bush, R. Wise, K.W. Domier, K. Kasha, A. Laroche, G. Scole, S. Molnar, and G. Fedak. 1993. Reproducibility of random amplified DNA (RAPD) analysis among laboratories. PCR Methods Appl. 2:341-345.

Rohlf, F.J. and R.R. Sokal. 1981. Comparing numerical taxonomic studies. Syst. Zool. 30:459-490.

Ruter, B., J.L. Hamrick, and B.W. Wood. 1999. Genetic diversity within provenance and cultivar germplasm collections versus natural populations of pecan (Carya illinoinensis). J. Hered. 90:521-528.

Thompson, T.E. and L.J. Grauke. 1991. Pecans and other hickories (Carya), p. 839-904. In: J.N. Moore and J.R. Ballington (eds.). Genetic resources of temperate fruit and nut crops. Intl. Soc. Hort. Sci., Wageningen. 